\title{
Dry-mix autoclaved lunar concrete from lower-Ti basalt lunar regolith simulant
}

\author{
Lixiong Cai ${ }^{\mathrm{a}, *}$, Lieyun Ding ${ }^{\mathrm{a}}$, Hanbin $\mathrm{Luo}^{\mathrm{a}}$ \\ ${ }^{a}$ School of Civil Engineering and Mechanics, Huazhong University of Science and Technology, Wuhan, China
}

\begin{abstract}
To build a permanently inhabited base on the Moon is a vitally important step to developing deep space exploration and lunar colonization. Therefore, indigenous materials become a significant requirement for lunar construction as transporting the construction materials from Earth is extremely expensive. Fortunately, construction materials can be fabricated by utilizing in-situ materials on the Moon. Dry mix autoclaving is a feasible process for lunar construction material manufacture. In this study, the influence of calcareous material ratio, LRS fineness and briquetting pressure on mechanical property was discussed to estimating the most appropriate technological parameter. The strength forming mechanism was expounded by the investigation of hydration products. The result shows that introducing appropriate amount of high-activity calcium materials can improve the strength and promote the generation of target hydration products. Meanwhile, the increasing of LRS fineness resulted in weakening of compressive strength which may ascribe to the decreasing compactness caused by the trapped gas during forming process with finer particles. The increment of briquetting pressure enhanced compressive strength in a certain range. However, it should be implemented after comprehensive consideration of the enhancing effect. This research provides support for preparation of autoclaved lunar construction materials in the near future.
\end{abstract}

(C) 2018 The Authors. Published by Diamond Congress Ltd., Budapest University of Technology and Economics Peer-review under responsibility of the scientific committee of the Creative Construction Conference 2018.

Keywords: Lunar construction; dry-mix autoclaving; lunar regolith simulant; mechanical property; hydration products

\section{Introduction}

The long-term vision for space exploration includes developing human habitats and conducting scientific investigations on planetary bodies, especially on Moon and Mars. Lunar construction is a vitally important step in the exploration and colonization of the Moon and even the solar system [1]. Ascribing to the adverse effect of harsh environment on unprotected humans, the indoor environment has to be insulated from vacuum, radiation, extreme temperatures, dust, and meteoroids et al, by a protective structure [2]. Fabricating construction material in harsh Moon environment, especially vacuum and extreme temperature, with limited kind of resource and energy is extremely difficult.

Dry Mix/Steam Injection (DM/SI) technology is another feasible method for developing concrete on the moon. In DM/SI method, the dry mixture particles gradually heated and embraced by the hot steam, meanwhile, part of the steam being forced infiltrate into the inner regions of the component via the micropores, the mixture particles gain activation energy and moisture condensed from steam, undergo rapidly and hydration gradually. The DM/SI method has significant advantages than the wet mixing method, such as lower water and cement needed, faster and more thorough hydration and much shorter curing time. Meanwhile, DM/SI method prevented the material from being exposed to the vacuum and thus avoids the rapid evaporation of water [3]. The DM/SI method products can achieve higher strength than conventional cured products mainly owe to the more generating of C-S-H gel which resulted in

Corresponding author: Lixiong Cai email: cailixiong @ hust.edu.cn 
a denser concrete structure [4,5]. Steaming technology can be separated into unsaturated and saturated steam curing. Unsaturated steam curing was commonly known as steam curing, and saturated steam curing with certain pressure was always named autoclaving process in term of material science. In this paper, the steam technology is referring to the autoclaving process.

The utilization of steaming technology in lunar construction material manufacture was firstly proposed and delivered promising results in 1989 by T.D. Lin and Su N [3,6]. T.D. Lin proposed the procedure of DM/SI process to overcome the ill-suited vacuum condition. The test program was carried out by National Chiao Tung University with cement and Ottawa sand. The concrete developed $700 \mathrm{kgf} / \mathrm{cm}^{2}(10000 \mathrm{psi})$ after 18 hours of saturated steaming at $180^{\circ} \mathrm{C}$. The compressive strength is approximately 2.5 times and half cement requirement to the conventional wetmix procedure [7]. Nan Su of National Yunlin University of Science and Technology have discussed the characteristics and engineering properties of dry-mix/steam-injection concrete with cement and standard sand. The optimal steaming temperature for dry-mix samples of cement and standard sand is $180-200^{\circ} \mathrm{C}$ and the optimal steaming scenario for $10 \mathrm{~cm}^{3}$ samples of concrete is at $200^{\circ} \mathrm{C}$ for $18 \mathrm{~h}$. The present DM/SI method has advantages of lower cement content, shorter hardening time and higher concrete strengths, as compared to normal temperature wetmix method [8]. S. Wilhelm and M. Curbach has verified the DM/SI method with lunar regolith simulant JSC-1A, which generated a compressive strength of $10.7 \mathrm{~N} / \mathrm{mm}^{2}$ and a water-cement ratio of 0.45 was calculated after one day procedure [9]. The steam injection hydration of high alumina cement concrete (mortar) and Ottawa sand has been characterized by D M Pakulski and K J Knox in 1992, a compressive strength of about $30 \mathrm{~N} / \mathrm{mm}^{2}$ after steaming for $25 \mathrm{~min}$ at $130^{\circ} \mathrm{C}$ and $0.2 \mathrm{~N} / \mathrm{mm}^{2}$ steam pressure was achieved [10].

But above all, all of the researches were introducing cement as calcareous materials, ignored that the essence of the hydrothermal synthesis reaction is the hydration reaction between alkalinity calcium hydroxide $\left(\mathrm{Ca}(\mathrm{OH})_{2}-\mathrm{CH}\right)$ and acidity oxide silicon $\left(\mathrm{SiO}_{2}, \mathrm{Al}_{2} \mathrm{O}_{3}\right.$, etc.). In addition, almost no research was considered the raw material chemical composition and mechanism of hydrothermal synthesis of raw materials based on complex mineral system design, and less on the influence of different particle size distribution of the research.

This research presented an autoclaved construction material prepared from lunar regolith simulant (LRS) and calcium hydroxide $(\mathrm{CH})$ with saturated vapor pressure curing. The influence of calcareous material ratio, LRS fineness and briquetting pressure on compressive strength was discussed to estimating an appropriate mixture proportion and forming pressure. Meanwhile, the hydration products of $\mathrm{CH}$ and LRS autoclaved lunar construction material were determined to expounding the strength mechanism. This research provides support for preparation of autoclaved lunar construction materials in the near future.

\section{Raw materials and methods}

\subsection{Raw materials}

The major raw material LRS was collected and pretreated as the research of Zheng Yongchun et al [11]. The calcareous material was calcium hydroxide $(\mathrm{CH})$ which was chemically pure reagent produced by Sinopharm Chemical Reagent Co., Ltd. The content of $\left(\mathrm{Ca}(\mathrm{OH})_{2}\right)$ was exceed $99.95 \%$.

\subsection{Mixture proportion}

The mixture proportion of each specimen was shown in Table1. Group D1-D9 was set to determine a more appropriate mix proportion. Group D7, D10, D11 were carried out to evaluating the effect of LRS fineness of the mechanical properties of the final products. Finally, the effect of briquetting pressure was determined according to mixture proportion in Group D7. 
Table 1 Mixture proportion of specimens

\begin{tabular}{cccccc}
\hline No & Calcium hydroxide & LRS & LRS Fineness & $\mathrm{Ca} / \mathrm{Si}$ & $\mathrm{K}_{\text {alk }}$ \\
\hline D1 & $0 \%$ & $100 \%$ & 0.18 & 0.09 \\
D2 & $5 \%$ & $95 \%$ & 0.26 & 0.18 \\
D3 & $6 \%$ & $94 \%$ & 0.28 & 0.2 \\
D4 & $7 \%$ & $93 \%$ & & 0.30 & 0.22 \\
D5 & $8 \%$ & $92 \%$ & & 0.32 & 0.24 \\
D6 & $9 \%$ & $91 \%$ & & 0.34 & 0.26 \\
D7 & $10 \%$ & $90 \%$ & 0.36 & 0.28 \\
D8 & $15 \%$ & $85 \%$ & & 0.47 & 0.39 \\
D9 & $20 \%$ & $80 \%$ & & 0.60 & 0.51 \\
D10 & $10 \%$ & $90 \%$ & $<150 \mathrm{Mesh}$ & & \\
D11 & $10 \%$ & $90 \%$ & $<200 \mathrm{Mesh}$ & & 0.36 \\
\hline
\end{tabular}

\subsection{Specimen preparation}

The materials were first weighed according to the mixture proportion, and then mixed in an electric mixer for 3 mins. The mixture was decanted into a cylinder pelleting mould and compacted with press machine at specified pressure $(50 \mathrm{KN})$ and dwell time $(10 \mathrm{~s})$. After that, put the rough-body into an autoclave for steaming process. The autoclaving saturated vapor pressure was maintained at $1.4 \mathrm{MPa}$, corresponding to $190^{\circ} \mathrm{C}$, for $8 \mathrm{~h}$. After arriving at the designated maintenance time, turning off the power and waiting for the chamber cool down to room temperature to take out the specimens.

\subsection{Characterization}

The chemical component of LRS was detected by X-ray fluorescence spectrometer. The specific surface area of LRS was carried out according to GB/T 8074-2008. The granulometric distribution of LRS was determined by laser particle size analyzer, Marlvern Mastersizer 2000. The compressive strength was measured by a concrete compression testing machine with $\pm 1 \%$ error. The morphology of hydration product was characterized by using JEM-2100F field-emission high resolution transmission electron microscopy (FESEM) and energy dispersive X-ray (EDX). The mineral constituent of LRS and autoclaved product were detected by a D/8 Adwance X-ray diffractometer with $\mathrm{Cu} \mathrm{K} \alpha$ radiation from $5^{\circ}-70^{\circ}$. The parameters of the characteristic peak of autoclaved samples were determined by Jade 5.0.

\section{Results and discussion}

\subsection{Lunar regolith simulant}

The chemical component of LRS was shown in Table 2, meanwhile, the morphology and mineral composition was presented in Fig1 and Fig 2, respectively. From the analysis of LRS particle morphology, the ground LRS particles were angular, which is ascribe to the brittleness of basaltic material in the grinding process. The dominant oxides in LRS were $\mathrm{SiO}_{2}, \mathrm{Al}_{2} \mathrm{O}_{3}, \mathrm{Fe}_{2} \mathrm{O}_{3}, \mathrm{CaO}$ and $\mathrm{MgO}$, accompany with $\mathrm{Na}_{2} \mathrm{O}, \mathrm{K}_{2} \mathrm{O}, \mathrm{TiO}_{2}, \mathrm{MnO}$ and $\mathrm{P}_{2} \mathrm{O}_{5}$. From the angle of mineral composition, LRS mainly consisted of feldspar, pyroxene and olivine which existed by $63.5 \%$, $22.3 \%$ and $8.1 \%$, respectively, according to CAS-1 lunar soil simulant [11]. The LRS with different fineness were achieved by grinding and filtrating process and the granular characteristics of LRS presented in Fig 3. 
Table 2 chemical component of LRS

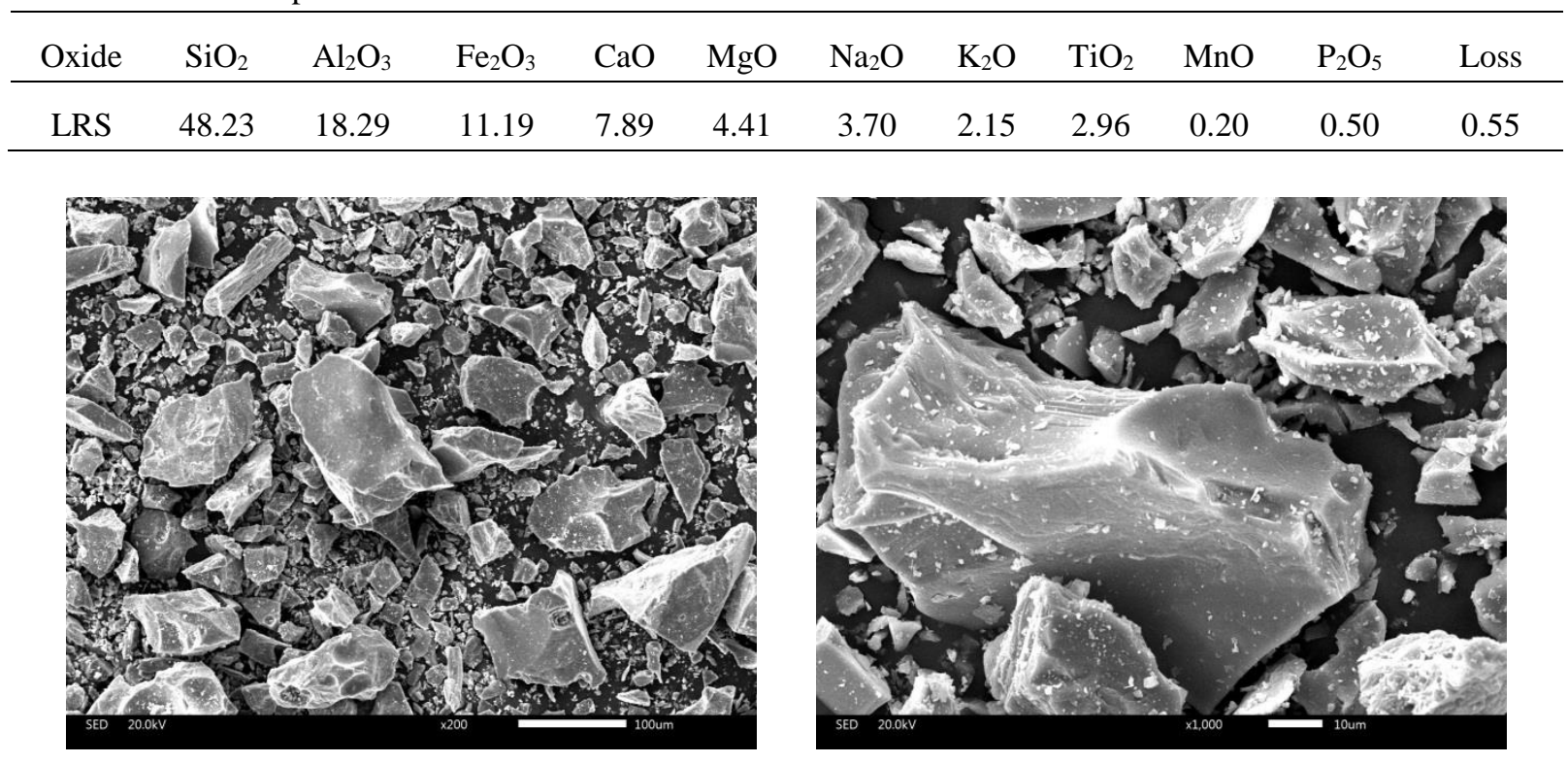

Fig 1 Morphology of LRS particles

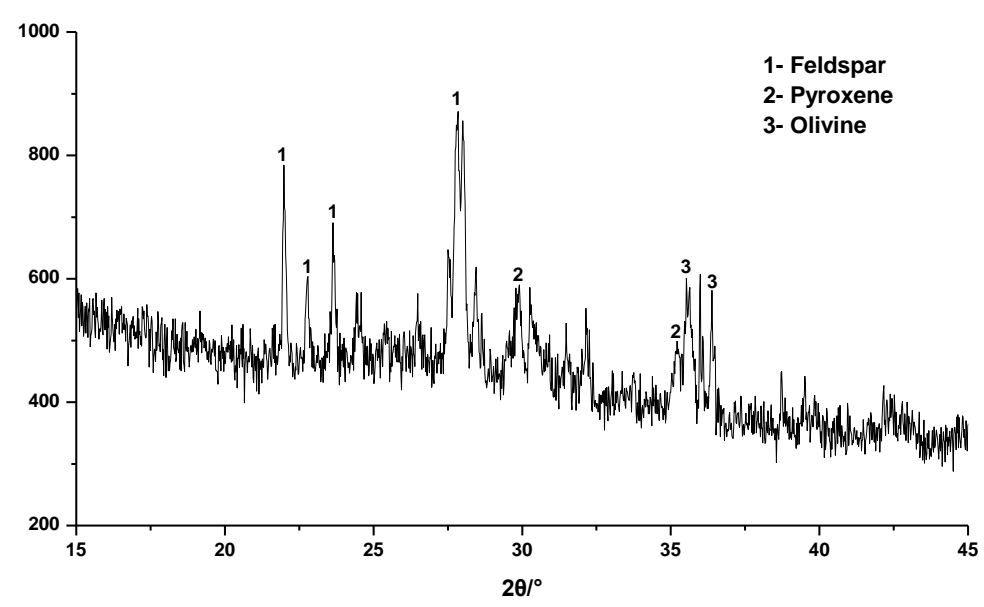

Fig 2 Mineralogical analysis of LRS 


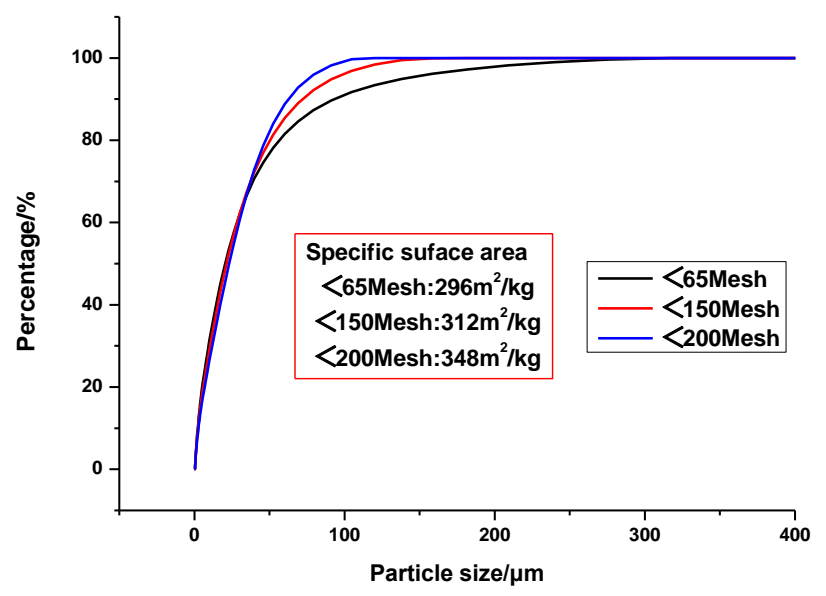

Fig 3 Granular characteristics of LRS

\subsection{Chemical analysis}

In term of chemical and mineralogical composition, LRS is a multi-mineral material with $\mathrm{SiO}_{2}$ and $\mathrm{Al}_{2} \mathrm{O}_{3}$ as main components and $\mathrm{CaO}$ and $\mathrm{MgO}$ as minor components. Therefore, the mixture proportion of autoclaving technology should refer to the alkaline coefficient $\left(K_{a l k}\right)$ between 0.8 1.2. The formula of $K_{\text {alk }}$ was shown in Eq.(1). The $K_{\text {alk }}$ of LRS was 0.03 , indicating that it was characteristically acidic, Consequently, alkaline correction materials, like calcium oxide $(\mathrm{CaO})$ and calcium hydroxide $\left(\mathrm{Ca}(\mathrm{OH})_{2}\right)$ should be added to modify the $\mathrm{K}_{\text {alk }}$ of the mixture to be a more appropriate value range for preparing autoclaved products. However, due to the dry mix process, addition of $\mathrm{CaO}$ will cause serious volume expansion during steam pressure curing process which cannot be neglected. Thus, $\mathrm{Ca}(\mathrm{OH})_{2}$ was chosen as the $\mathrm{K}_{\text {alk }}$ modification material [12].

$$
K_{\text {alk }}=\frac{\left[\left(\mathrm{CaO}+0.93 \mathrm{MgO}+0.6 \mathrm{R}_{2} \mathrm{O}\right)-\left(0.55 \mathrm{Al}_{2} \mathrm{O}_{3}+0.35 \mathrm{Fe}_{2} \mathrm{O}_{3}+0.7 \mathrm{SO}_{3}\right)\right]}{0.93 \mathrm{SiO}_{2}}
$$

\subsection{Calcareous material ratio}

The effect of calcareous material ratio on compressive strength was carried out to evaluate the most appropriate calcium-silicate ratio and $K_{\text {alk }}$ of dry-mix autoclaved lunar concrete from lower-Ti basalt lunar regolith simulant. Meanwhile, in consideration of the rarity of calcium hydroxide on the Moon, $\mathrm{CH}$ content should be as low as possible under sufficient strength.

The samples and compressive strength values were shown in Fig 4 and Fig 5, respectively. With the CH content increasing from $0 \%$ to $20 \%$, the surface of the sample gradually became dense, which indicated the improving reaction rate between LRS and $\mathrm{CH}$. Meanwhile, the compressive strength enhanced from quite brittle $(0.2 \mathrm{MPa})$ to high intensity (49.63MPa) also verified the regulation. Nevertheless, in view of sufficient strength and restricted $\mathrm{CH}$ supply, $10 \% \mathrm{CH}$ content was chosen as a reference group for the following experiment. Taking the long view, the performances of construction materials under lunar extreme environment still need further investigation. 


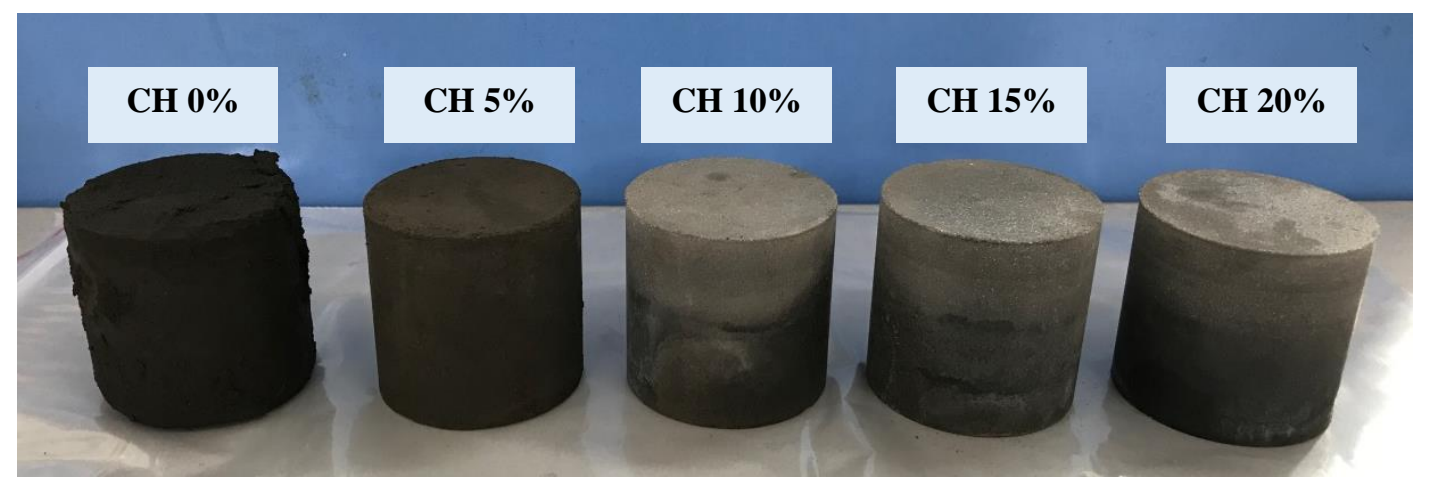

Fig 4 Specimens of different calcareous material ratio

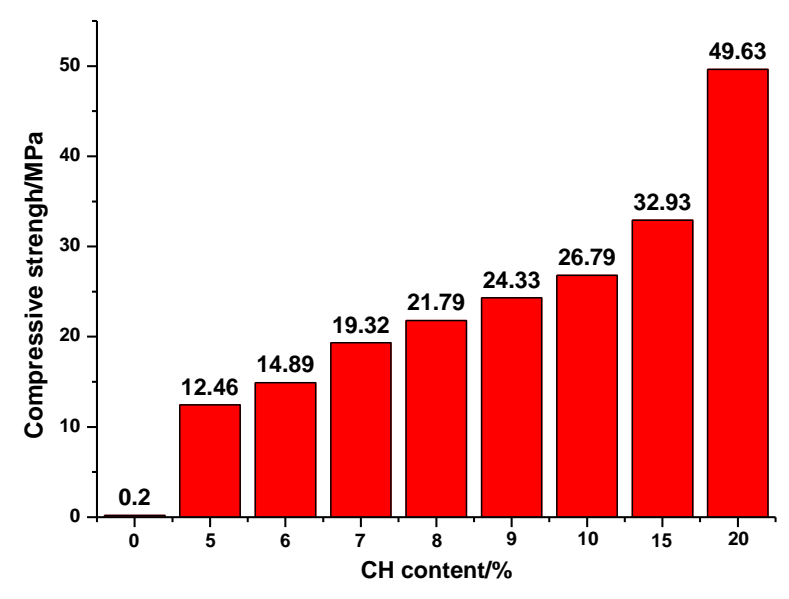

Fig 5 Compressive strength of different calcareous material ratio specimens

\subsection{Lunar regolith simulant fineness}

In consideration of the grinding and filtrating process on the moon is uncomplicated, and the supplying of various fineness lunar regolith is realizable. Meanwhile, from the angle of reaction activity, increasing fineness can improve mechanical properties to a certain extent. Therefore, the influence of LRS fineness was investigated to determine the optimal granularity characteristics of LRS for dry-mix autoclaved lunar concrete.

The samples and compressive strength values were presented in Fig 6 and Fig 7, respectively. It can be seen that with the finer of LRS, it cannot tell obvious difference from appearance, but an anomalous regulation revealed in the compressive strength value. The weakening of compressive strength may ascribe to the decreasing compactness which caused by the trapped gas during forming process with finer particles. Nevertheless, this problem can be effectively avoided in the ultra-high vacuum environment on the Moon. On all accounts, powder compacting component has an optimized particle size distribution range, not pursue the reaction activity blindly, but neglected the problem of powder filtration and formation. 


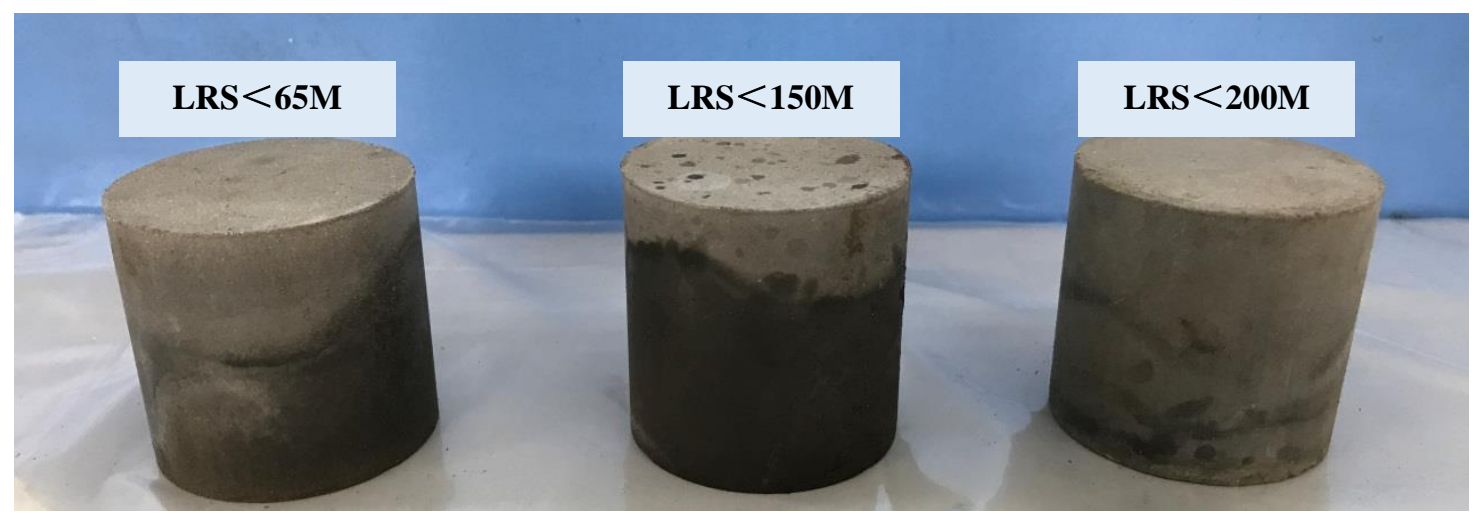

Fig 6 Specimens of different LRS fineness

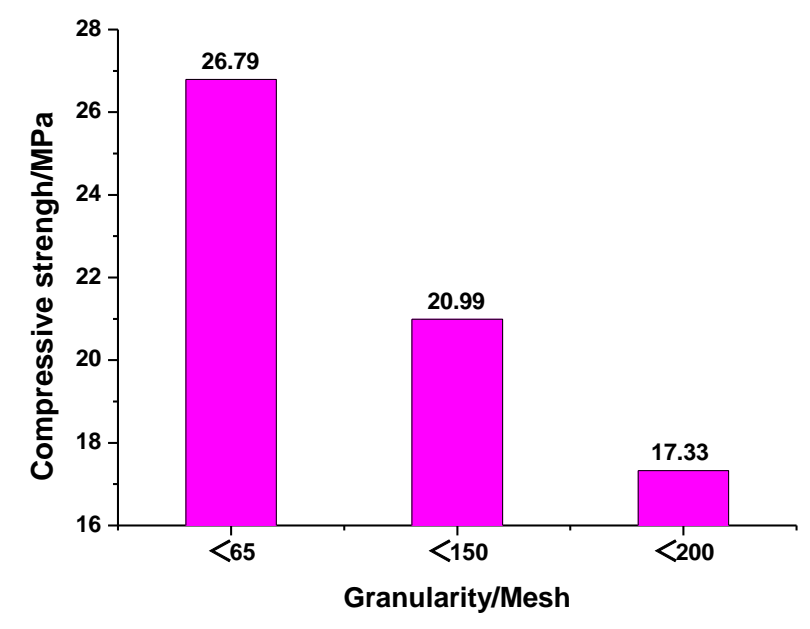

Fig 7 Compressive strength of different LRS fineness specimens

\subsection{Briquetting pressure}

On account of the influence of different briquetting pressure $(25 \mathrm{KN}, 50 \mathrm{KN}, 75 \mathrm{KN}, 100 \mathrm{KN})$ on compactness, and finally resulted in different density and compressive strength, it was investigated to determine a better molding force value. The result was presented in Fig 8. It can tell that with the briquetting pressure gained from $25 \mathrm{KN}$ to $100 \mathrm{KN}$, the compressive strength enhanced from 20.09MPa to $29.53 \mathrm{MPa}$. When briquetting pressure enlarged from $25 \mathrm{KN}$ to $50 \mathrm{KN}$, the compressive strength increased more than 33\%. Nevertheless, keep on increasing briquetting pressure to $100 \mathrm{KN}$ can improve the compressive strength by only $10 \%$. Therefore, the increment of briquetting pressure should be implemented after comprehensive consideration of the enhancing effect. 


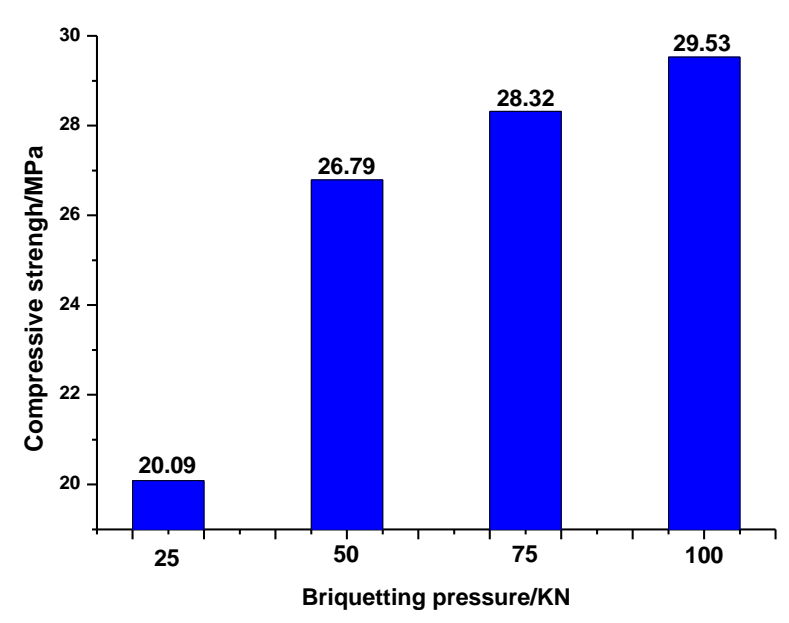

Fig 8 Compressive strength of different briquetting pressure specimens

\subsection{Analysis of hydration products}

In order to figure out the morphology features and mineral composition of dry-mix autoclaved lunar concrete from lower-Ti basalt lunar regolith simulant, analysis of hydration products was carried out by FESEM-EDS and XRD method, respectively.

The morphology of sample D7 was presented in Fig 9 and Fig 10, and the elemental quantitative analysis was listed in Table 3. As Fig 9 shown, plenty dough-like phase which supposed to be C-S-H gel (Spot2) adhered to LRS particles, meanwhile, some areas has formed faveolated crystal which should be low crystallinity tobermorite (Spot1). As the 5000 times magnified picture in Fig 10, flake-like products (Spot 3) were generated on LRS particles which believed to be well crystallinity tobermorite(Spot 4). The particles were adhered with adjacent by C-S-H gel and tobermorite which resulted in interconnected structure and acquire strength.

As the mineralogical analysis of sample D7 in Fig 11, besides the unreacted minerals of LRS, adscititious $\mathrm{Ca}(\mathrm{OH})_{2}(4.9 \AA, 2.67 \AA)$ and generated tobermorite $(11.3 \AA, 3.08 \AA)$ were also detected in the autoclaved products. The amorphous C-S-H gel cannot came into sharp feature peaks but emerged broadened "convex closure" between $26 \sim 34^{\circ}$. Thus, the mineralogical analysis presented the similar mineral composition with morphology analysis.

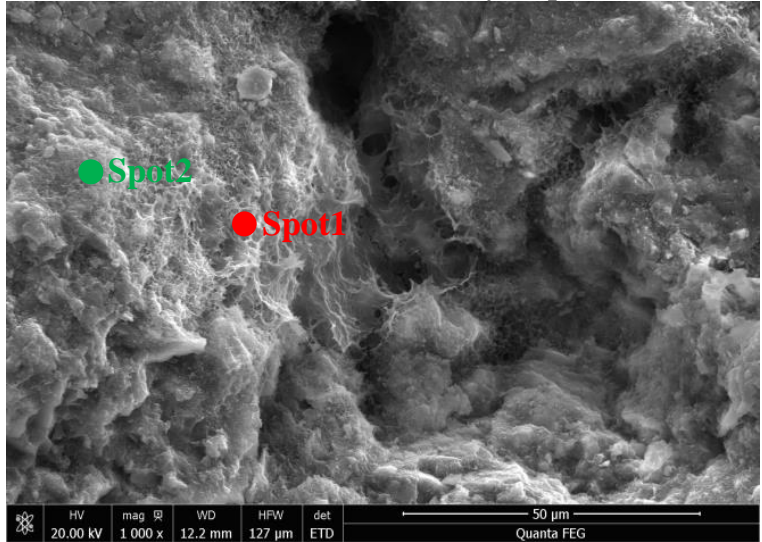

Fig 9 Mineral morphology of sample 7 ( I )

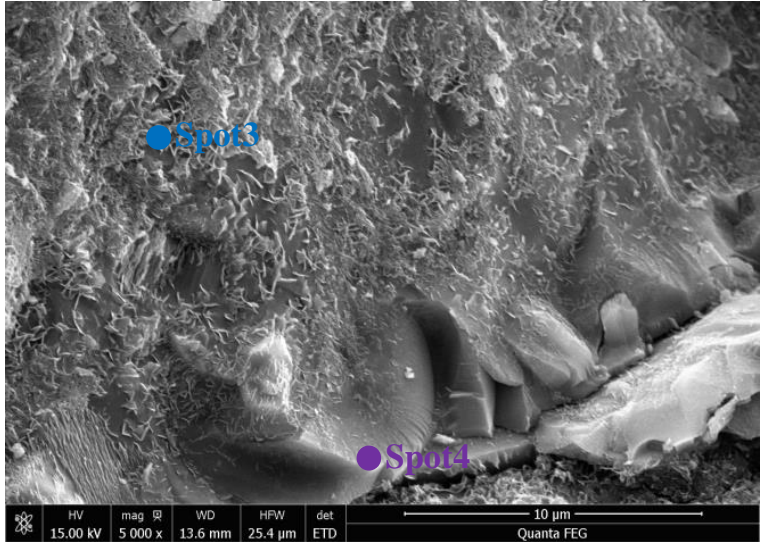

Fig 10 Mineral morphology of sample 7 ( II ) 
Table 3 Elemental quantitative analysis

\begin{tabular}{rcccccccc}
\hline \multirow{2}{*}{ Elements } & \multicolumn{2}{c}{ Spot1 } & \multicolumn{2}{c}{ Spot2 } & \multicolumn{2}{c}{ Spot3 } & \multicolumn{2}{c}{ Spot4 } \\
\cline { 2 - 8 } & Weight/\% & Atom/\% & Weight/\% & Atom/\% & Weight/\% & Atom/\% & Weight/\% & Atom/\% \\
\hline $\mathrm{Ca}$ & 10.94 & 6.04 & 9.32 & 5.30 & 6.94 & 3.88 & 4.74 & 2.54 \\
$\mathrm{Si}$ & 17.62 & 13.87 & 18.42 & 14.96 & 21.62 & 17.24 & 21.10 & 16.12 \\
$\mathrm{O}$ & 44.04 & 60.89 & 40.02 & 57.03 & 41.46 & 58.03 & 45.78 & 61.39 \\
$\mathrm{Al}$ & 7.42 & 6.08 & 6.97 & 5.89 & 8.25 & 6.85 & 9.38 & 7.46 \\
$\mathrm{Mg}$ & 3.84 & 3.49 & 6.22 & 5.83 & 3.44 & 3.17 & 2.42 & 2.14 \\
$\mathrm{Na}$ & 4.53 & 4.36 & 4.32 & 4.29 & 4.68 & 4.56 & 5.87 & 5.48 \\
$\mathrm{Fe}$ & 7.39 & 2.93 & 10.38 & 4.24 & 8.01 & 3.21 & 5.48 & 2.10 \\
\hline
\end{tabular}

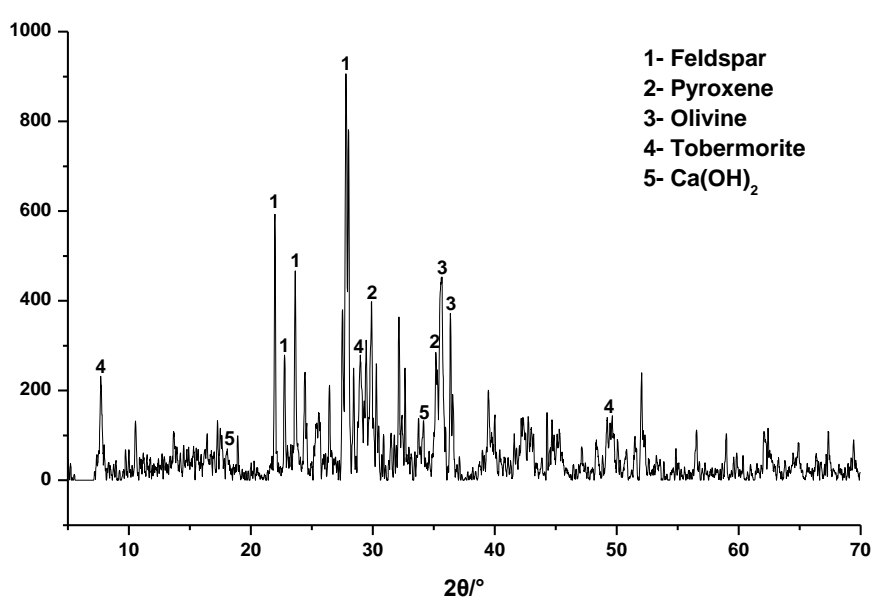

Fig 11 Mineralogical analysis of sample 7

\section{Conclusion}

This paper investigated the influence of calcareous material ratio, LRS fineness and briquetting pressure on mechanical property; meanwhile, the hydration products were determined to expounding the strength mechanism. The following conclusions can be drawn:

(1) The increasing of $\mathrm{CH}$ content effectively enhanced the compressive strength. However, finer of LRS has adverse effect on the mechanical property. Although, increment of briquetting pressure can improve mechanical property in a certain range, it should be implemented after comprehensive consideration of the enhancing effect.

(2) Through autoclaving process, mainly generated amorphous C-S-H gel, faveolated low crystallinity tobermorite and flake-like well crystallinity tobermorite. The strength was attributed to the interconnected structure formed by adhering of C-S-H gel and tobermorite.

\section{Acknowledgement}

The authors express the gratitude to State Key Laboratory of Silicate Materials for Architectures (Wuhan University of Technology) for supply of laboratory, equipment and the open fund project (SYSJJ2018-17). 


\section{References}

[1] Ian A. Crawford, and K. H. Joy. "Lunar exploration: opening a window into the history and evolution of the inner Solar System." Philosophical Transactions 372.2024(2014):20130315.

[2] Vaniman, D., Reedy, R., Heiken, G., Olhoeft, G., \& Mendell, W. The lunar environment. The lunar Sourcebook, CUP (1991), 27-60.

[3] T. D. Lin. Dry-mix/steam-injection method for producing high-strength concrete in one day. ACI Special Publication SP149-37, 149:665-677, 1994.

[4] W. M. Lin, T. D Lin, C. L Hwang, et al. Fundamental study on hydration of cement and cement minerals with steam. ACI Materials Journal, 95.1(1998):37-49.

[5] W. M. Lin, C. L Hwang, Y. N Peng: Characteristics of microhydrates formed under steam conditions. ACI Materials Journal, 2000, vol. 97, No. 3, pp. 309-324.

[6] T D Lin, N Su: Concrete construction on the moon. Engineering, Construction, and Operations in Space III, 1992.

[7] T D Lin, T Liang, S Chou, et al. Lunar Concrete Made with The Dry-Mix/Steam-Injection Method. Engineering, Construction, and Operations in Space V. ASCE, 2014:592-599.

[8] N Su, Y. N. Peng. The characteristics and engineering properties of dry-mix/steam-injection concrete. Cement \& Concrete Research 31.4(2001):609-619.

[9] S. Wilhelm, and M. Curbach. "Manufacturing of Lunar Concrete by Steam." Earth and Space 2014: Engineering for Extreme Environments 2015.

[10] D M Pakulski, K J Knox. Steam injection system for lunar concrete. Engineering, Construction, and Operations in Space III. ASCE, 1992:1347-1358.

[11] Zheng Yongchun, Wang Shijie, Ouyang Ziyuan et al. CAS-1 lunar soil simulant. Advances in Space Research 43.3(2009):448-454.

[12] B Du, C Zhou, Z Dan, et al. Preparation and characteristics of steam-autoclaved bricks produced from electrolytic manganese solid waste. Construction \& Building Materials, 2014, 50(1):291-299. 